\title{
Congenital brain abnormalities during a Zika virus epidemic in Salvador, Brazil, April 2015 to July 2016
}

Mariana Kikuti ${ }^{1,2}$, Cristiane W. Cardoso ${ }^{3}$, Ana P.B. Prates 3 , Igor A.D. Paploski ${ }^{1,2}$, Uriel Kitron ${ }^{1,4}$, Mitermayer G. Reis ${ }^{1,2}$,

Ganeshwaran H. Mochida ${ }^{5,6,7}$, Guilherme S. Ribeiro ${ }^{1,2}$

1. Fundação Oswaldo Cruz, Salvador, Brazil

2. Universidade Federal da Bahia, Salvador, Brazil

3. Secretaria Municipal de Saúde de Salvador, Salvador, Brazil

4. Emory University, Atlanta, United States

5. Boston Children's Hospital, Boston, United States

6. Massachusetts General Hospital, Boston, United States

7. Harvard Medical School, Boston, United States

Correspondence: Guilherme S. Ribeiro (guilherme.ribeiro@bahia.fiocruz.br)

Citation style for this article:

Kikuti Mariana, Cardoso Cristiane W., Prates Ana P.B., Paploski Igor A.D., Kitron Uriel, Reis Mitermayer G., Mochida Ganeshwaran H., Ribeiro Guilherme S.. Congenital brain abnormalities during a Zika virus epidemic in Salvador, Brazil, April 2015 to July 2016. Euro Surveill. 2018;23(45):pii=1700757. https://doi. org/10.2807/1560-7917.ES.2018.23.45.1700757

Background: North-eastern Brazil was the region most affected by the outbreak of congenital Zika syndrome that followed the 2015 Zika virus (ZIKV) epidemics, with thousands of suspected microcephaly cases reported to the health authorities, mostly between late 2015 and early 2016. Aim: To describe clinical and epidemiological aspects of the outbreak of congenital brain abnormalities (CBAs) and to evaluate the accuracy of different head circumference screening criteria in predicting CBAs. Method: Between April 2015 and July 2016, the Centers for Information and Epidemiologic Surveillance of Salvador, Brazil investigated the reported cases suspected of microcephaly and, based on intracranial imaging studies, confirmed or excluded a diagnosis of CBA. Sensitivity, specificity and positive and negative predictive values of different head circumference screening criteria in predicting CBAs were calculated. Results: Of the 365 investigated cases, 166 (45.5\%) had confirmed CBAs. The most common findings were intracranial calcifications and ventriculomegaly in $143(86.1 \%)$ and $111(66.9 \%)$ of the 166 CBA cases, respectively. Prevalence of CBAs peaked in December 2015 (2.24 cases/10o live births). Cases of CBAs were significantly more likely to have been born preterm and to mothers who had clinical manifestations of arboviral infection during pregnancy. None of the head circumference screening criteria performed optimally in predicting CBAs. Conclusion: This study highlights the magnitude of neurological consequences of the ZIKV epidemic and the limitations of head circumference in accurately identifying children with CBA. Gestational symptoms compatible with ZIKV infection should be combined with imaging studies for efficient detection of suspect CBAs during ZIKV epidemics.

\section{Introduction}

Early in 2015, large outbreaks of acute exanthematous illness were detected in several states in north-eastern Brazil. By April 2015, Zika virus (ZIKV) was identified as the aetiology of the illness $[1,2]$. A few months after the epidemic peak in May 2015, an increase in newborns with microcephaly was noted in north-eastern Brazil [3] and promptly gathered global attention due to a possible link between gestational ZIKV infection and microcephaly. Since then, evidence for a causal association between in utero exposure to ZIKV and microcephaly and other neurological complications has emerged [4-6]. The constellation of clinical manifestations of congenital ZIKV infection may be referred to as 'congenital Zika syndrome' [7].

In light of the surge of microcephaly cases, the Brazilian Ministry of Health $(\mathrm{BMoH})$ declared a national public health emergency in November 2015 and initiated a surveillance programme for identification of suspected microcephaly cases [8]. All health facilities were required to report such cases [8-10] and encouraged to report spontaneous abortions and stillbirths in women with a history of a rash during pregnancy, in a national reporting system. Although head circumference was immediately adopted as the primary criterion for screening cases suspected of congenital abnormalities by Zika, not all children with neurological impairment due to ZIKV present with microcephaly at birth [11]. Therefore, it is important to understand how well the criteria used to detect microcephaly can predict the congenital brain alterations of ZIKV.

Here, we describe the characteristics of the cases with congenital brain abnormalities (CBAs) confirmed by intracranial imaging studies among the reported cases 
Epidemic curve of the reported cases suspected of microcephaly per week of birth by status of congenital brain abnormality $^{\mathrm{a}}$, Salvador, Brazil, April 2015-July $2016\left(\mathrm{n}=631^{\mathrm{b}}\right)$

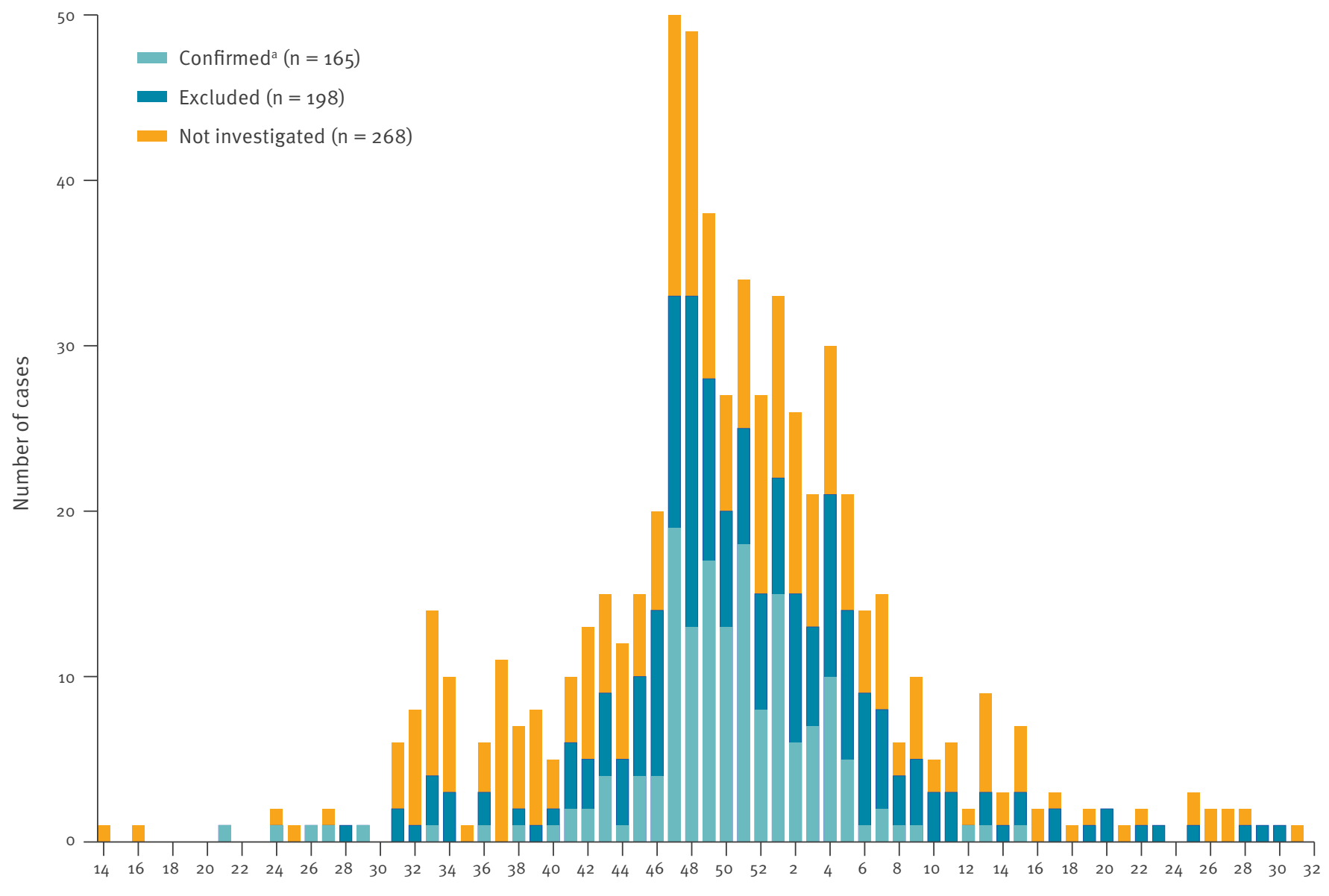

Epidemiological week 2015-2016

\footnotetext{
${ }^{a}$ Confirmation based on intracranial imaging studies.

b The 631 suspected cases depicted are those with available data on date of birth.
}

of suspected microcephaly in Salvador, Brazil. We also identified clinical manifestations during pregnancy that were associated with CBAs, and evaluated the accuracy of different screening criteria based on head circumference for predicting CBAs.

\section{Methods}

Suspected microcephaly case definition for mandatory reporting

From 17 November to 11 December 2015, the $\mathrm{BMoH}$ defined suspected microcephaly cases as newborns with head circumference measures $\leq 33 \mathrm{~cm}$ for term $\left(\geq 37\right.$ weeks) or $<3^{\text {rd }}$ percentile of the Fenton Preterm Growth Chart for preterm ( 337 weeks) [8] and required mandatory reporting of newborns fulfilling this case definition. This criterion was also applied to cases who were retrospectively identified during this period.
From 12 December 2015 to 12 March 2016, the suspected case definition was updated as newborns with head circumference $\leq 32 \mathrm{~cm}$ for term and the previous criteria for preterm newborns were maintained [9]. Lastly, on 13 March 2016, the suspected microcephaly case definition was changed to newborns with head circumference $<3^{\text {rd }}$ percentile of the World Health Organization (WHO) Child Growth Standards for term and $<3^{\text {rd }}$ percentile of the INTERGROWTH- $21^{\text {st }}$ standards for preterm [10]. Mandatory reporting was performed based solely on head circumference parameters of the newborns, regardless of a Zika diagnosis of the mothers. However, reporting of spontaneous abortions, stillbirths or pregnancies with any detected alterations in the fetal central nervous system in women with a self-reported history of rash during pregnancy was also encouraged regardless of head circumference, but not mandatory $[9,10]$. 


\begin{tabular}{|c|c|c|c|c|}
\hline \multirow{3}{*}{ Clinical characteristics } & \multicolumn{4}{|c|}{ Congenital brain abnormalities diagnosis } \\
\hline & \multicolumn{2}{|c|}{ Confirmed $(n=166)$} & \multicolumn{2}{|c|}{ Excluded $(n=199)$} \\
\hline & $\mathrm{n}$ & $\%$ & $\mathrm{n}$ & $\%$ \\
\hline Male sex & 76 & 45.8 & 65 & 32.7 \\
\hline \multicolumn{5}{|l|}{ Gestational age at birth $^{\mathrm{a}}$} \\
\hline < 37 weeks & 54 & 33.3 & 13 & 7.0 \\
\hline $37-42$ weeks & 108 & 66.7 & 172 & 93.0 \\
\hline \multicolumn{5}{|l|}{ Head circumference } \\
\hline Head circumference $(\mathrm{cm})$, median and $\mathrm{IQR}^{\mathrm{b}, \mathrm{c}}$ & 30.0 & $28.0-31.0$ & 32.0 & $31.0-32.0$ \\
\hline Head circumference $(\mathrm{cm}), \min -\mathrm{max}^{\mathrm{b}, \mathrm{c}}$ & \multicolumn{2}{|c|}{$21.5-42.0$} & \multicolumn{2}{|c|}{$28.0-36.0$} \\
\hline \multicolumn{5}{|l|}{ Intracranial imaging performed } \\
\hline Ultrasound & 136 & 81.9 & 192 & 96.5 \\
\hline Computed tomography & 53 & 31.9 & 9 & 4.5 \\
\hline Magnetic resonance imaging & 17 & 10.2 & 4 & 2.0 \\
\hline \multicolumn{5}{|c|}{ Image findings consistent with congenital malformations } \\
\hline Intracranial calcifications & 143 & 86.1 & o & 0.0 \\
\hline Ventriculomegaly & 111 & 66.9 & 0 & 0.0 \\
\hline Agenesis of the corpus callosum & 20 & 12.1 & o & 0.0 \\
\hline Dysgenesis of the corpus callosum & 19 & 11.5 & o & 0.0 \\
\hline Lissencephaly & 17 & 10.2 & 0 & 0.0 \\
\hline Cerebellar abnormalities $^{d}$ & 9 & 5.4 & o & 0.0 \\
\hline Anencephaly & 3 & 1.8 & o & 0.0 \\
\hline \multicolumn{5}{|l|}{ Other findings } \\
\hline Oligohydramnios & 17 & 10.2 & 7 & 3.5 \\
\hline Intrauterine growth restriction & 14 & 8.4 & 2 & 1.0 \\
\hline Subependymal cysts & 16 & 9.6 & 7 & 3.5 \\
\hline Arthrogryposis & 11 & 6.6 & 0 & 0.0 \\
\hline Auditory abnormalities ${ }^{\mathrm{e}}$ & 20 & 19.2 & 10 & 11.5 \\
\hline Ophthalmological abnormalities ${ }^{f}$ & 13 & 18.8 & 3 & 4.5 \\
\hline Death $^{\mathrm{g}}$ & 6 & 3.6 & 0 & 0.0 \\
\hline
\end{tabular}

IQR: interquartile range.

Suspected microcephaly cases may have undergone more than one imaging testing and presented with more than one finding.

${ }^{a}$ Data available for 162 confirmed cases and 185 excluded cases. The lowest gestational age for the confirmed and excluded cases were 20 and 30 weeks, respectively.

${ }^{b}$ Data on head circumference were not available for two confirmed cases. Data on head circumference of three confirmed cases and eight excluded cases were not considered in the analysis due to a late measurement without a precise date ( $>28$ days post birth).

' Some of the cases from both groups of confirmed and excluded congenital brain abnormalities diagnosis had a head circumference size greater than the screening limits used to detect microcephaly. This is because reporting cases of spontaneous abortions, stillbirths or pregnancies with any detected alterations in the fetal central nervous system in women with self-reported history of rash during pregnancy was also encouraged, though not mandatory.

${ }^{d}$ Cerebellar vermis agenesis or cerebellar hypoplasia.

e Data on auditory abnormalities were available for 104 confirmed cases ( 86 by auditory screening method, three by brainstem evoked response audiometry test (BERA) and 15 by both) and for 87 excluded cases ( 79 by auditory screening method, three by BERA test and five by both).

${ }^{f}$ Data on ophthalmological abnormalities were available for 69 confirmed cases and for 67 excluded cases. Among the confirmed cases, two had pigmentary abnormalities in macula, one abnormal red reflex, one bilateral chorioretinal atrophy and optic disc hypoplasia, one cataracts, one macular atrophy, one corneal excoriation, one chorioretinitis, one optic disc excavation, one coloboma, and three without information on type of abnormality. Among excluded cases, one had retinal haemorrhage, one retinal excavation and one cataracts.

${ }^{\mathrm{g}}$ Death occurred on the day of birth for two cases, within 2 days for one case, within 2 months for two cases and within 4 months for one case.

\section{Investigation of reported cases suspected of microcephaly}

Salvador, the fourth largest city in Brazil, was one of the north-eastern cities most affected by the microcephaly epidemic [3]. The Salvador Centers for Information and Epidemiologic Surveillance (CIES) is the branch of the
Municipal Secretary of Health in charge of the investigation of the reported suspected cases. Investigations were performed by reviewing medical records for intracranial imaging studies. In addition, mothers of reported suspect microcephaly cases were interviewed about clinical manifestations during pregnancy using a 
TABLE 2

Maternal clinical characteristics of suspected microcephaly cases, Salvador, Brazil, April 2015-July 2016 (n=365)

\begin{tabular}{|c|c|c|c|c|c|c|c|}
\hline \multirow{3}{*}{ Characteristics } & \multicolumn{4}{|c|}{ Congenital brain abnormalities diagnosis } & \multirow{3}{*}{ OR } & \multirow{3}{*}{$95 \% \mathrm{Cl}$} & \multirow{3}{*}{$\mathrm{p}$ value } \\
\hline & \multicolumn{2}{|c|}{$\begin{array}{l}\text { Confirmed } \\
(n=166)\end{array}$} & \multicolumn{2}{|c|}{$\begin{array}{l}\text { Excluded } \\
(n=199)\end{array}$} & & & \\
\hline & $\mathrm{n} / \mathrm{N}^{\mathrm{a}}$ & $\%$ & $\mathrm{n} / \mathrm{N}^{\mathrm{a}}$ & $\%$ & & & \\
\hline Mother's age in years, median and IQR ${ }^{b}$ & 26 & $21-32$ & 25 & $21-31$ & NA & NA & 0.38 \\
\hline \multicolumn{8}{|l|}{ Type of gestation } \\
\hline Multifetal & $5 / 163$ & 3.1 & 4/195 & 2.0 & 1.51 & $0.32-7.74$ & \multirow{2}{*}{0.54} \\
\hline Single & $158 / 163$ & 96.9 & $191 / 195$ & 98.0 & 1 & NA & \\
\hline \multicolumn{8}{|l|}{ Symptoms during pregnancy } \\
\hline Fever $^{\mathrm{c}}$ & $66 / 155$ & 42.3 & $42 / 187$ & 22.5 & 2.56 & $1.56-4.21$ & $<0.001$ \\
\hline Exanthema & $118 / 161$ & 73.3 & $68 / 193$ & 35.2 & 5.04 & $3.12-8.19$ & $<0.001$ \\
\hline \multicolumn{8}{|l|}{ Trimester of exanthema $^{d}$} \\
\hline First trimester & $75 / 108$ & 69.4 & $25 / 57$ & 43.9 & 2.91 & $1.42-5.97$ & \multirow{2}{*}{0.001} \\
\hline Second or third trimester & $33 / 108$ & 30.6 & $32 / 57$ & 56.1 & 1 & NA & \\
\hline \multicolumn{8}{|c|}{ Other arboviral-infection-like symptoms reported during pregnancy } \\
\hline Pruritus & $72 / 133$ & 54.1 & $36 / 143$ & 25.2 & 3.51 & $2.05-6.04$ & $<0.001$ \\
\hline Arthralgia & $60 / 135$ & 44.4 & $31 / 143$ & 21.7 & 2.89 & $1.66-5.06$ & $<0.001$ \\
\hline Myalgia & $51 / 135$ & 37.8 & $25 / 142$ & 17.6 & 2.84 & $1.58-5.17$ & $<0.001$ \\
\hline Headache & $48 / 133$ & 36.1 & $25 / 142$ & 17.6 & 2.64 & $1.46-4.83$ & 0.001 \\
\hline Retro-orbital pain & $24 / 133$ & 18.1 & $6 / 142$ & 4.2 & 4.99 & $1.89-15.38$ & $<0.001$ \\
\hline Conjunctival hyperaemia & $21 / 133$ & 15.8 & $9 / 142$ & 6.3 & 2.77 & $1.16-7.14$ & 0.01 \\
\hline
\end{tabular}

NA: not applicable; Cl: confidence interval (95\%); IQR: interquartile range; OR: odds ratio.

a The denominators in this column may vary as they are based on the number of cases with known information on the characteristic in question.

b Data on mothers' ages were not available for nine confirmed and four excluded cases.

c Fever was defined as axillary temperatures of $\geq 37.8^{\circ} \mathrm{C}$.

d Data on trimester of exanthema are presented for the mothers who had exanthema ( $n=118$ for the mothers of confirmed congenital brain abnormality cases, and $n=68$ for those of the excluded cases). For 10 confirmed and 11 excluded cases the trimester of the exanthema was unknown.

standardised questionnaire [10]. After concluding the investigation, CIES updated the national reporting system with the obtained information.

\section{Image-confirmed congenital brain abnormality case definition}

In the present study, we analysed data on suspected microcephaly cases investigated by CIES up to 13 September 2016. According to the availability of data on prenatal or postnatal intracranial imaging studies, the reported cases were classified as either investigated or not investigated. Investigated cases whose intracranial ultrasound, computed tomography, or magnetic resonance imaging results reported intracranial calcifications, ventriculomegaly, dysgenesis or agenesis of the corpus callosum, lissencephaly, cerebellar abnormalities, or anencephaly were classified as confirmed CBA cases. Reports of hydrocephalus or colpocephaly were consolidated as ventriculomegaly. Suspected microcephaly cases that underwent imaging studies and did not exhibit any of the previous findings were excluded from consideration as CBA cases.

\section{Statistical analysis}

An epidemiological curve of the temporal distribution of the suspected microcephaly cases stratified according to the confirmation status was constructed by epidemiological week of the date of birth. Records with incomplete information on date of birth were excluded from the epidemiological curve. Prevalence of CBA per month was calculated dividing the number of imaging confirmed cases by the monthly number of live births from mothers residing in Salvador. To estimate the average annual prevalence of CBA, we divided the CBA prevalence calculated for the complete study period by the number of months in the study period and multiplied the result by 12 . Live birth data were obtained at the National Birth Registration System (SINASC) [12].

Clinical characteristics of confirmed and excluded cases of CBA were presented as frequencies and medians. Two-tailed Fisher exact test and odds ratios with $95 \%$ confidence intervals $(\mathrm{Cl})$ were used to test for differences in the frequencies of clinical characteristics of suspected cases and gestational characteristics of cases' mothers between confirmed and excluded CBA cases. The Wilcoxon rank test was used to test 
Imaging findings of confirmed congenital brain abnormalities cases, according to the timing of maternal exanthema, Salvador, Brazil, April 2015-July $2016(\mathrm{n}=151)$

\begin{tabular}{|c|c|c|c|c|c|c|c|c|}
\hline \multirow{3}{*}{ Congenital brain abnormalities } & \multicolumn{8}{|c|}{ Pregnancy trimester of exanthema } \\
\hline & \multicolumn{2}{|c|}{$\begin{array}{l}\text { First } \\
(n=75)\end{array}$} & \multicolumn{2}{|c|}{$\begin{array}{l}\text { Second } \\
(n=24)\end{array}$} & \multicolumn{2}{|c|}{$\begin{array}{l}\text { Third } \\
(n=9)\end{array}$} & \multicolumn{2}{|c|}{$\begin{array}{l}\text { Without exanthema } \\
\qquad(\mathrm{n}=43)\end{array}$} \\
\hline & $\mathrm{n}$ & $\%$ & $\mathrm{n}$ & $\%$ & $\mathrm{n}$ & $\%$ & $\mathrm{n}$ & $\%$ \\
\hline Intracranial calcifications & 68 & 90.7 & 23 & 95.8 & 7 & 77.8 & 32 & 74.4 \\
\hline Ventriculomegaly & 48 & 64.0 & 18 & 75 & 8 & 88.9 & 28 & 65.1 \\
\hline Agenesis of the corpus callosum & 11 & 14.7 & 3 & 12.5 & 2 & 22.2 & 4 & 9.3 \\
\hline Dysgenesis of the corpus callosum & 8 & 10.7 & 5 & 20.8 & 0 & 0.0 & 5 & 11.6 \\
\hline Lissencephaly & 6 & 8.0 & 4 & 16.7 & 2 & 22.2 & 4 & 9.3 \\
\hline Cerebellar abnormalities $^{\mathrm{a}}$ & 6 & 8.0 & 1 & 4.2 & 0 & 0.0 & 1 & 2.3 \\
\hline Arthrogryposis & 6 & 8.0 & 2 & 8.3 & 0 & 0.0 & 2 & $4 \cdot 7$ \\
\hline Oligohydramnios & 12 & 16.0 & 1 & 4.2 & 0 & 0.0 & 3 & 7.0 \\
\hline Intrauterine growth restriction & 9 & 12.0 & 3 & 12.5 & 0 & 0.0 & 1 & 2.3 \\
\hline Subependymal cysts & 7 & 9.3 & 1 & 4.2 & 1 & 11.1 & 6 & 14.0 \\
\hline
\end{tabular}

a Cerebellar vermis agenesis or cerebellar hypoplasia.

for difference in maternal age and head circumference between confirmed and excluded CBA cases. In order to investigate whether the imaging-detected $C B A s$ varied according to the presumptive timing of infection during pregnancy, the frequencies of each imaging abnormality in confirmed cases were compared according to the presence and timing of exanthema during pregnancy. A two-tailed significance level of 0.05 was set.

Imaging-confirmed and excluded CBA cases were used to assess the accuracy of different head circumference microcephaly screening criteria for prediction of CBAs. The microcephaly screening criteria evaluated were those adopted by the $\mathrm{BMoH}$ from (i) November to 11 December 2015 [8]; (ii) from 12 December 2015 to 12 March 2016 [9]; and (iii) from 13 March 2016 to the present [10]; as well as (iv) the screening criteria recommended by the Pan American Health Organisation ( $<-2$ standard deviation (SD) of the Fenton Preterm Growth Chart according to sex and gestational age for preterm newborns and $<3^{\text {rd }}$ percentile of the WHO Child Growth Standards according to sex for term newborns) [13]; (v) the Fenton Preterm Growth Chart ( $1-2$ SD according to sex and gestational age) [14]; (vi) the INTERGROWTH$21^{\text {st }}$ standards ( $<-2$ SD according to sex and gestational age) [15]; and (vii) the WHO Child Growth Standards for term newborns ( $1-2$ SD according to sex for term newborns) [16]. Some of the criteria require detailed information on gestational age (weeks and days) but gestational age was recorded in full weeks in our dataset. We used the number of weeks plus o days in such cases. Accuracy of the criteria in predicting imagingconfirmed CBAs was assessed by calculating sensitivity, specificity, positive and negative predictive values, and their respective $95 \% \mathrm{Cls}$. Records with no information on head circumference, gestational age, or with late reporting ( $>28$ days post birth) without a precise date on which head circumference was measured were excluded from the accuracy analysis. Data were analysed with Stata 14 [17].

\section{Ethics statement}

This investigation was performed using de-identified secondary data obtained by routine activities of the Epidemiological Surveillance Office/Municipal Secretariat of Health from Salvador, Bahia, Brazil. The Salvador Secretariat of Health and the Oswaldo Cruz Foundation Ethics Committee approved the study and granted a waiver of signed informed consent.

\section{Results}

By 13 September 2016, Salvador CIES had received 650 reports of suspected microcephaly cases, who were born between April 2015 and July 2016. Of these, review of medical records to retrieve results of intracranial imaging studies was completed for 365 cases. Among those, 166 (45.5\%) had imaging findings consistent with a diagnosis of CBA, while 199 (54.5\%) did not. The epidemiological curve of the temporal distribution of reported cases (built for 631 cases with available data on date of birth) peaked between week 47 of 2015 (22-28 November) and week 4 of 2016 (24-30 January) for both the suspected microcephaly reported cases and the imaging-confirmed CBA cases (Figure 1). Prevalence of imaging-confirmed CBA was 1.22 cases per 100 live births in November 2015, 2.24 cases per 100 live births in December 2015, and 1.55 cases per 100 live births in January 2016. Prevalence of imagingconfirmed CBA for the whole study period (April 2015 to July 2016) was 0.34 per 100 live births and the oneyear adjusted annual prevalence of image-confirmed CBA was estimated as 0.26 per 100 live births. The 
last CBA case confirmed by imaging studies during the study period was born in epidemiological week 15 of 2016 (10-16 April).

Male sex was more frequent among the imaging-confirmed CBA cases (45.8\%) than among excluded cases (32.7\%) (odds ratio (OR): 1.74; 95\% Cl: 1.11-2.72; $\mathrm{p}=0.01$ ) (Table 1). Confirmed cases were more likely to have been born preterm ( $<37$ weeks) (OR: 6.62; 95\% Cl: 3.35-13.79; $p<0.001$ ) and had a lower head circumference median (30 cm; interquartile range (IQR): 28-31) compared with excluded cases (32 cm; IQR: 31-32) ( $p<0.001)$. Confirmed cases also had a broader head circumference range (range: $21.5 \mathrm{~cm}-42 \mathrm{~cm}$ vs $28 \mathrm{~cm}$ $-36 \mathrm{~cm} ; \mathrm{p}$ <0.001). The most frequent CBAs observed among confirmed cases were intracranial calcifications (86.1\%) and ventriculomegaly (66.9\%) (Table 1). Agenesis of the corpus callosum (12.1\%), dysgenesis of the corpus callosum (11.5\%), lissencephaly (10.2\%), cerebellar abnormalities (5.4\%), and anencephaly $(1.8 \%)$ were identified in a minority of the confirmed cases. Of note, intracranial calcifications were associated with other brain lesions, being present in $83.8 \%$ (93/111) of those with ventriculomegaly, but in $19.7 \%$ (50/254) of those without it; in 94.1\% (16/17) and $36.5 \%(127 / 348)$ of those with and without lissencephaly, in $94.7 \%(18 / 19)$ and $36.1 \%(125 / 346)$ of those with and without dysgenesis of the corpus callosum, and in $85.0 \%(17 / 20)$ and $36.5 \%(126 / 345)$ of those with and without agenesis of the corpus callosum ( $p<0.001$ for all the comparisons). In terms of other findings, arthrogryposis was found in $6.6 \%$ of the confirmed cases, but in none of the excluded cases. Oligohydramnios, intrauterine growth restriction, subependymal cysts, and auditory and ophthalmological abnormalities were also statistically more frequent among the confirmed than the excluded cases (Table 1). Intracranial calcifications were also more frequently observed among those with arthrogryposis than among those without it $(72.7 \%(8 / 11)$ vs $38.1 \%(135 / 354))$ and among those with oligohydramnios than among those without it (66.7\% (16/24) vs 37.2\% (127/341)) ( $p<0.001$ for both comparisons).

Maternal age at birth and type of gestation (single vs multifetal) were not associated with imaging confirmation of CBAs (Table 2). Frequency of exanthema during pregnancy among mothers of children in the confirmed group was $73.3 \%$. Among those, $69.4 \%$ had the rash during the first trimester and $30.6 \%$ during the second or third trimester $(22.2 \%$ during the second and $8.3 \%$ during the third). Mothers of children in the confirmed CBA group were more likely to have had exanthema during pregnancy (OR: $5.04 ; 95 \% \mathrm{Cl}$ : 3.12-8.19) than mothers of children whose diagnosis of CBA was excluded, especially in the first trimester (OR: $2.91 ; 95 \% \mathrm{Cl}: 1.42-5.97$ ) when compared with the second and third trimester. All other symptoms commonly observed during arboviral infections were more frequent during pregnancy on the mothers of children in the confirmed group (Table 2 ).
When the confirmed cases were classified according to the timing of maternal rash during pregnancy (first, second, third trimester or no rash), there were no statistically significant differences in the frequency of CBAs, nor in the frequency of arthrogryposis, oligohydramnios, and intrauterine growth restriction, between the four groups. An exception was observed for calcifications, that were more frequently present when exanthema occurred during first trimester than when compared with mothers who did not present exanthema during pregnancy $(p=0.02)$ (Table 3$)$.

Among the different head circumference criteria used to screen for microcephaly, the first criterion adopted by the BMoH from November 2015 to December 2015 was the one with the highest sensitivity (83.6\%) and lowest specificity $(7.3 \%)$ in predicting the presence of CBAs (Table 4). On the other hand, the INTERGROWTH$21^{\text {st }}$ standards had the lowest sensitivity $(63.4 \%)$ and highest specificity $(72.4 \%)$. Positive predictive value was the highest for the INTERGROWTH-21 ${ }^{\text {st }}$ standards $(63.9 \%)$ and the lowest for the criterion adopted by BMoH from December 2015 to March 2016 (41.1\%). Negative predictive value was the highest for the WHO Child Growth Standards (77.8\%) and the lowest for the $\mathrm{BMoH}$ criterion used between November and December 2015 (36.1\%).

\section{Discussion}

In this study, we described a high prevalence of confirmed CBAs in Salvador, as high as $2.2 \%$ of the live births in December 2015. The prevalence of imageconfirmed CBA estimated for the study period adjusted for one year was 52 times higher than the estimated baseline prevalence of microcephaly in the north-east region (average of 5 cases per 100,000 live births per year, between 2000 and 2014) [18]. Unfortunately, we did not have information on serological or virological ZIKV testing, which would allow ascertaining the aetiology of such an outbreak. However, the peak of births of babies with microcephaly occurred 30-33 weeks after the peak of ZIKV epidemic in Salvador [3], and this is consistent with the growing body of evidence suggesting that the first trimester of pregnancy is the period when ZIKV infections pose the highest risk of adverse fetal outcome $[3,19,20]$. Taken together, it is reasonable to assume that most of the imaging-confirmed cases in this study were due to congenital ZIKV infection.

As we only considered cases with specific neuroimaging findings as confirmed cases, we certainly underestimated cases of congenital ZIKV infection. Several suspected cases had not been investigated by the time we analysed the data and the imaging modality most commonly used was prenatal or postnatal intracranial ultrasound, which is not an optimal modality to detect abnormalities of the corpus callosum and cerebral cortex. In addition, suspected microcephaly cases were reported based on birth head circumference, which could be well within normal limits in some cases of congenital ZIKV infection [11]. Although reporting of 
spontaneous abortions, stillbirths and fetuses presenting alterations in the central nervous system was also encouraged, allowing us to confirm a few cases with normal or large head circumference at birth, we could not evaluate whether there was an increase in abortions and stillbirths in Salvador during the study period. On the other hand, some cases counted as confirmed could be due to other causes such as congenital cytomegalovirus infection or genetic disorders, but the number of these cases is expected to be small, considering the baseline rate of microcephaly before the epidemic. In addition, in north-east Brazil (a region in which Salvador was one of the epicenters for the ZIKV outbreak), only $1.3 \%$ of confirmed cases of infectionrelated microcephaly during the 2015-16 period had laboratory evidence of syphilis, toxoplasmosis, cytomegalovirus, or herpes simplex [21].

A similar increase in microcephaly cases was reported in other locations where ZIKV epidemics have occurred, such as Colombia, where the prevalence of microcephaly also increased around 6 months after the peak of ZIKV transmission in July 2016. However, the microcephaly prevalence reported in Colombia peaked at 17.7 cases per 10,000 live births, much lower than observed in Salvador [22]. Potential reasons for this difference may include, variable intensity levels of ZIKV transmission, differences in circulating ZIKV strains and different case definitions and surveillance criteria. Further, co-circulation of other arboviruses (dengue and chikungunya, for example), differences in mosquito control measures, and prior exposure to yellow fever vaccination could be contributing factors $[22,23]$. Additionally, Brazil was the first country in the Americas to experience a large outbreak of ZIKV and to detect an increase in microcephaly cases, and this allowed other countries as Colombia to issue recommendations for delaying pregnancies, which might have resulted in decreased risk of congenital abnormalities associated with ZIKV infection during pregnancy [22].

Female newborns were overrepresented among the reported cases who had a CBA diagnosis excluded. This finding may be due to the application of the same head circumference screening criteria for reporting boys and girls suspected of microcephaly until 12 March 2016 (period during which $85 \%$ of the suspect cases had been reported), since head circumference of girls tend to be smaller than boys at the same gestational age [24]. We also found that the frequency of preterm births among the confirmed CBA cases was significantly greater than in excluded cases. Although this finding suggests that congenital Zika syndrome could be associated with preterm birth, we could not determine from the available data whether the early births were natural in their occurrence or due to a medical decision in the presence of fetal anomalies and distress.

The most frequent imaging findings among the confirmed cases were intracranial calcifications and ventriculomegaly. Although these findings are not specific for congenital Zika syndrome, they have been frequently observed among laboratory-confirmed cases of congenital Zika syndrome [25-28]. Anencephaly has not been previously reported among laboratory-confirmed cases of congenital ZIKV infection, and further studies are warranted to determine if it is part of the spectrum of the congenital Zika syndrome. Auditory and ocular manifestations were present in approximately $20 \%$ of the confirmed cases. However, they were also found in lower frequencies among the suspected microcephaly cases with normal intracranial imaging studies. Since these manifestations have been linked to congenital ZIKV infection $[29,30]$, it is important to further investigate whether ZIKV infection can cause auditory or ocular lesions in the absence of structural malformations in the brain and to monitor for long-term consequences in ZIKV-exposed babies born with no alterations in brain imaging studies. In addition, as preterm babies may have more auditory and visual complications than term babies, we investigated whether these sensory disorders were associated with premature delivery and found a higher frequency of auditory abnormalities among preterm than term babies (26.5\% vs $11.4 \%$; $p=0.01$ ), but this difference was not observed for ophthalmological abnormalities. Further studies are necessary to determine the specific contribution of both prematurity and ZIKV-related neurological injury on the occurrence of sensory disorders in these children.

Frequency of exanthema during pregnancy among mothers of children in the confirmed group was $73.3 \%$. It has been previously estimated that only $20 \%$ of the ZIKV infections are symptomatic [31], but other studies have shown similarly high frequencies of exanthema among mothers who gave birth to children with congenital Zika syndrome $[7,32,33]$. Recall bias and the surveillance system associating a rash during pregnancy as a marker for microcephaly risk may have accounted for the high proportion of symptomatic women in this series. However, both confirmed and excluded CBA cases originated from the same reported dataset and only $35.2 \%$ of the mothers of children in the excluded group reported a rash, representing a significant difference. Therefore, it is likely that symptomatic ZIKV infection during pregnancy truly poses a higher risk of CBAs. Similar findings of an association of rash during pregnancy with increased CBA risk was previously reported in Brazil [7,32,33], although an absence of such association was noted in the United States (US) [34].

Among mothers of children in the confirmed group who reported a history of rash during pregnancy, $69.4 \%$ had the rash during the first trimester, but, in addition, $22.2 \%$ had rash during the second trimester and $8.3 \%$ during the third trimester. Data linking ZIKV infection in the second and third trimester to congenital malformations are still scarce $[27,32]$, and our findings reinforce that second and third trimester infections may also lead to congenital Zika syndrome with CBAs. 
Head circumference-based criteria were primarily used during the epidemic of congenital ZIKV infection. These can be easily applied in any clinical setting and do not require any special equipment. Although microcephaly in general is a risk factor for developmental delay, according to the US National Collaborative Perinatal Project, which followed a cohort of newborns, only $11 \%$ of children with microcephaly (head circumference $\leq-2 \mathrm{SD}$ ) at birth had $\mathrm{IQ} \leq 70$ at 7 years of age [35], suggesting that microcephaly has a relatively low specificity in predicting poor neurodevelopmental outcome in the general population. Further, cases with congenital ZIKV infection without microcephaly at birth have been reported [36]. On the other hand, the severity of anomalies in neuroimaging during the neonatal period has been shown to have a good prognostic value for predicting poor developmental outcomes in symptomatic congenital cytomegalovirus infection [37,38], which shares many clinical and radiological similarities to congenital ZIKV infection. Therefore, it is important to evaluate the accuracy of different microcephaly criteria in predicting CBAs.

In this regard, none of the criteria performed particularly well. Overall, the INTERGROWTH- $21^{\text {st }}$ standards had a better performance, with sensitivity, specificity and positive and negative predictive values over $60 \%$. A significantly low specificity of the criteria used by the $\mathrm{BMoH}$ until 11 March 2016 was also noted. There is only one small prior study with 31 cases that used imaging findings consistent with congenital infection as the reference criteria for sensitivity estimation of different head circumference criteria [39]. Compared with this prior study, our study revealed lower sensitivity and much lower specificity. Combined with relatively low positive and negative predictive values, these data clearly demonstrate the limitations of head circumference in accurately identifying children with CBA during ZIKV epidemics.

Novel screening methods for congenital Zika syndrome during ZIKV epidemics that incorporate additional parameters to head circumference are urgently needed in order to detect the maximum number of affected children and fetuses for further specific health assistance, without compromising specificity $[40,41]$. Prenatal and postnatal intracranial ultrasound triage performed by experienced ultrasonographers may be an efficient approach during outbreaks, especially for women who experienced symptoms consistent with ZIKV infection during pregnancy. However, the importance of clinical examination and follow-up of newborns, as well as development of better serological and molecular tests, cannot be understated.

Our study highlights the magnitude of neurological consequences of the ZIKV epidemic in Salvador, Brazil, further delineates congenital Zika syndrome, and identifies limitations of screening for congenital Zika syndrome based on head circumference that was performed during the recent epidemics. Follow-up studies of children with and without microcephaly or congenital abnormalities, who were exposed to ZIKV in utero are needed to fully understand the full spectrum of congenital Zika syndrome.

\section{Acknowledgements}

We thank health professionals in Salvador, Brazil, especially those working in surveillance activities, those providing healthcare for children born with congenital malformations and those providing support for affected children's families. We also thank the children reported as suspected cases of Zika congenital syndrome and their parents.

The Brazilian National Council of Technological and Scientific Development, the Brazilian Coordination for the Improvement of Higher Education, the Bahia Foundation for Research Support, the National Institute of Neurological Disease and Stroke, the Manton Center for Orphan Disease Research, Boston Children's Hospital Faculty Career Development Award and the David Rockefeller Center for Latin American Studies at Harvard University provided funding for the study, but they played no role in data analyses.

\section{Conflict of interest}

None declared.

Authors' contributions

MK, CWC, APBP, UK, MGR, and GSR conceived the study;

CWC and APBP provided access to the data;

MK and IADP analysed the data;

UK and GSR oversaw data analysis;

MK, GHM, and GSR wrote first draft of the manuscript;

MK, CWC, APBP, IADP, UK, MGR, GHM, and GSR participated in the discussion of the study and critical reviewed and approved the final manuscript.

\section{References}

1. Campos GS, Bandeira AC, Sardi SI. Zika Virus Outbreak, Bahia, Brazil. Emerg Infect Dis. 2015;21(10):1885-6. https://doi. org/10.3201/eid2110.150847 PMID: 26401719

2. Zanluca C, Melo VC, Mosimann ALP, Santos GI, Santos CN, Luz K. First report of autochthonous transmission of Zika virus in Brazil. Mem Inst Oswaldo Cruz. 2015;110(4):569-72. https:// doi.org/10.1590/0074-02760150192 PMID: 26061233

3. Paploski IAD, Prates APPB, Cardoso CW, Kikuti M, Silva MMO, Waller LA, et al. Time Lags between Exanthematous Illness Attributed to Zika Virus, Guillain-Barré Syndrome, and Microcephaly, Salvador, Brazil. Emerg Infect Dis. 2016;22(8):1438-44. https://doi.org/10.3201/eid2208.160496 PMID: 27144515

4. Rasmussen SA, Jamieson DJ, Honein MA, Petersen LR. Zika Virus and Birth Defects--Reviewing the Evidence for Causality. N Engl J Med. 2016;374(20):1981-7. https://doi.org/10.1056/ NEJMsr1604338 PMID: 27074377

5. de Araújo TVB, Rodrigues LC, de Alencar Ximenes RA, de Barros Miranda-Filho D, Montarroyos UR, de Melo APL, et al. Association between Zika virus infection and microcephaly in Brazil, January to May, 2016: preliminary report of a casecontrol study. Lancet Infect Dis. 2016;16(12):1356-63. https:// doi.org/10.1016/S1473-3099(16)30318-8 PMID: 27641777

6. Brasil P, Pereira JP Jr, Moreira ME, Ribeiro Nogueira RM, Damasceno L, Wakimoto M, et al. Zika Virus Infection in Pregnant Women in Rio de Janeiro. N Engl J 
Med. 2016;375(24):2321-34. https://doi.org/10.1056/ NEJMoa1602412 PMID: 26943629

7. Miranda-Filho DB, Martelli CMT, Ximenes RA, Araújo TVB, Rocha MAW, Ramos RCF, et al. Initial Description of the Presumed Congenital Zika Syndrome. Am J Public Health. 2016;106(4):598-600. https://doi.org/10.2105/ AJPH.2016.303115 PMID: 26959258

8. Secretaria de Vigilância em Saúde. Procedimentos preliminares a serem adotados para a vigilância dos casos de microcefalia no Brasil. [Preliminary procedures to be adopted for surveillance of microcephaly cases in Brazil]. Brasília - DF : Minisrério da Saúde ; 2015. Portuguese.

9. Secretaria de Vigilância em Saúde. Protocolo de vigilância e resposta à ocorrência de microcefalia relacionada à infecção pelo vírus zika [Protocol for surveillance and response to occurence of microcephaly related to Zika virus infection]. Brasília - DF: Ministério da Saúde; 2015. Portuguese. Available from: http://portalsaude.saude.gov.br/images/pdf/2015/ dezembro/og/Microcefalia---Protocolo-de-vigil--ncia-eresposta---vers--0-1----ogdez2015-8h.pdf

10. Secretaria de Vigilância em Saúde. Protocolo de vigilância e resposta à ocorrência de microcefalia relacionada à infecção pelo vírus zika [Protocol for surveillance and response to occurence of microcephaly related to Zika virus infection]. Brasília - DF: Ministério da Saúde; 2016. Portuguese. Available from: http://combateaedes.saude.gov.br/images/sala-desituacao/Microcefalia-Protocolo-de-vigilancia-e-resposta 10mar2016-18h.pdf

11. van der Linden V, Pessoa A, Dobyns W, Barkovich AJ, Júnior HV, Filho ELR, et al. Description of 13 Infants Born During October 2015-January 2016 With Congenital Zika Virus Infection Without Microcephaly at Birth - Brazil. MMWR Morb Mortal Wkly Rep. 2016;65(47):1343-8. https://doi.org/10.15585/mmwr. mm6547e2 PMID: 27906905

12. DATASUS. Sistema Nacional de Nascidos Vivos [Live Birth Information System]. Brasília - DF: Ministério da Saúde; 2016. Portuguese. [Accessed 11 Jun 2016]. Available from: http:// tabnet.datasus.gov.br/cgi/deftohtm.exe?sinasc/cnv/nvuf.def

13. Pan American Health Organization (PAHO). Lineamientos preliminares de vigilancia de microcefalia en recién nacidos en entornos con riesgo de circulación de virus Zika. [Preliminary guidelines for surveillance of microcephaly in newborns in environments with risk of Zika virus circulation]. WashingtonDC: PAHO; 2016.Portuguese.

14. Fenton TR, Kim JH. A systematic review and meta-analysis to revise the Fenton growth chart for preterm infants. BMC Pediatr. 2013;13(1):59. https://doi.org/10.1186/1471-2431-13-59 PMID: 23601190

15. Villar J, Cheikh Ismail L, Victora CG, Ohuma EO, Bertino E, Altman DG, et al. International standards for newborn weight, length, and head circumference by gestational age and sex: the Newborn Cross-Sectional Study of the INTERGROWTH21st Project. Lancet. 2014;384(9946):857-68. https://doi. org/10.1016/S0140-6736(14)60932-6 PMID: 25209487

16. World Health Organization (WHO). The WHO child growth standards. Geneva: WHO; 2016. [Accessed 31 Mar 2016]. Available from: http://www.who.int/childgrowth/en/

17. StataCorp. Stata Statistical Software: Release 14. College Station, TX: StataCorp LP; 2015.

18. Marinho F, de Araújo VEM, Porto DL, Ferreira HL, Coelho MRS, Lecca RCR, et al. Microcefalia no Brasil: prevalência e caracterização dos casos a partir do Sistema de Informações sobre Nascidos Vivos (Sinasc), 2000-2015. [Microcephaly in Brazil: prevalence and characterization of cases from the Live Birth Information System (Sinasc), 2000-2015]. Epidemiol e Serviços Saúde. 2016 Oct;25(4):701-12. Portuguese. Available from: http://www.iec.pa.gov.br/template_doi_ess. php?doi=10.5123/S1679-49742016000400701\& scielo $=$ S2237-96222016000400701

19. Kleber de Oliveira W, Cortez-Escalante J, De Oliveira WT, do Carmo GMI, Henriques CMP, Coelho GE, et al. Increase in Reported Prevalence of Microcephaly in Infants Born to Women Living in Areas with Confirmed Zika Virus Transmission During the First Trimester of Pregnancy - Brazil, 2015. MMWR Morb Mortal Wkly Rep. 2016;65(9):242-7. https://doi.org/10.15585/ mmwr.mm6509e2 PMID: 26963593

20. Cauchemez S, Besnard M, Bompard P, Dub T, Guillemette-Artur $P$, Eyrolle-Guignot D, et al. Association between Zika virus and microcephaly in French Polynesia, 2013-15: a retrospective study. Lancet. 2016;387(10033):2125-32. https://doi. org/10.1016/S0140-6736(16)00651-6 PMID: 26993883

21. de Oliveira WK, de França GVA, Carmo EH, Duncan BB, de Souza Kuchenbecker R, Schmidt MI. Infectionrelated microcephaly after the 2015 and 2016 Zika virus outbreaks in Brazil: a surveillance-based analysis. Lancet. 2017;390(10097):861-70. https://doi.org/10.1016/S01406736(17)31368-5 PMID: 28647172
22. Cuevas EL, Tong VT, Rozo N, Valencia D, Pacheco O, Gilboa SM, et al. Preliminary Report of Microcephaly Potentially Associated with Zika Virus Infection During Pregnancy Colombia, January-November 2016. MMWR Morb Mortal Wkly Rep. 2016;65(49):1409-13. https://doi.org/10.15585/mmwr. mm6549e1 PMID: 27977645

23. Butler D. Brazil asks whether Zika acts alone to cause birth defects. Nature. 2016;535(7613):475-6. https://doi. org/10.1038/nature.2016.20309 PMID: 27466104

24. Barbier A, Boivin A, Yoon W, Vallerand D, Platt RW, Audibert F, et al. New reference curves for head circumference at birth, by gestational age. Pediatrics. 2013;131(4):e1158-67. https://doi. org/10.1542/peds.2011-3846 PMID: 23509164

25. de Fatima Vasco Aragao M, van der Linden V, Brainer-Lima AM, Coeli RR, Rocha MA, Sobral da Silva P, et al. Clinical features and neuroimaging (CT and MRI) findings in presumed Zika virus related congenital infection and microcephaly: retrospective case series study. BMJ. 2016;353:11901. https:// doi.org/10.1136/bmj.i1901 PMID: 27075009

26. Hazin AN, Poretti A, Di Cavalcanti Souza Cruz D, Tenorio M, van der Linden A, Pena LJ, et al. Computed Tomographic Findings in Microcephaly Associated with Zika Virus. N Engl J Med. 2016;374(22):2193-5. https://doi.org/10.1056/NEJMc1603617 PMID: 27050112

27. Brasil P, Pereira JP Jr, Moreira ME, Ribeiro Nogueira RM, Damasceno L, Wakimoto $M$, et al. Zika Virus Infection in Pregnant Women in Rio de Janeiro. N Engl J Med. 2016;375(24):2321-34. https://doi.org/10.1056/ NEJMoa1602412 PMID: 26943629

28. Melo AS, Aguiar RS, Amorim MM, Arruda MB, Melo FO, Ribeiro ST, et al. Congenital zika virus infection: Beyond neonatal microcephaly. JAMA Neurol. 2016;73(12):1407-16. https://doi. org/10.1001/jamaneurol.2016.3720 PMID: 27695855

29. Leal MC, Muniz LF, Ferreira TSA, Santos CM, Almeida LC, Van Der Linden V, et al. Hearing Loss in Infants with Microcephaly and Evidence of Congenital Zika Virus Infection - Brazil, November 2015-May 2016. MMWR Morb Mortal Wkly Rep. 2016;65(34):917-9. https://doi.org/10.15585/mmwr.mm6534e3 PMID: 27585248

30. de Paula Freitas B, de Oliveira Dias JR, Prazeres J, Sacramento GA, Ko Al, Maia M, et al. Ocular Findings in Infants With Microcephaly Associated With Presumed Zika Virus Congenital Infection in Salvador, Brazil. JAMA Ophthalmol. 2016;1-19. PMID: 26865554

31. Duffy MR, Chen T-H, Hancock WT, Powers AM, Kool JL, Lanciotti RS, et al. Zika virus outbreak on Yap Island, Federated States of Micronesia. N Engl J Med. 2009;360(24):2536-43. https:// doi.org/10.1056/NEJMoa0805715 PMID: 19516034

32. França GVA, Schuler-Faccini L, Oliveira WK, Henriques CMP, Carmo EH, Pedi VD, et al. Congenital Zika virus syndrome in Brazil: a case series of the first 1501 livebirths with complete investigation. Lancet. 2016;388(10047):891-7. https://doi. org/10.1016/S0140-6736(16)30902-3 PMID: 27372398

33. Ventura CV, Maia M, Travassos SB, Martins TT, Patriota F, Nunes ME, et al. Risk Factors Associated With the Ophthalmoscopic Findings Identified in Infants With Presumed Zika Virus Congenital Infection. JAMA Ophthalmol. 2016;134(8):912-8. https://doi.org/10.1001/ jamaophthalmol.2016.1784 PMID: 27228275

34. Honein MA, Dawson AL, Petersen EE, Jones AM, Lee EH, Yazdy $M M$, et al. Birth Defects Among Fetuses and Infants of US Women With Evidence of Possible Zika Virus Infection During Pregnancy. JAMA. 2017;317(1):59-68. https://doi.org/10.1001/ jama.2016.19006 PMID: 27960197

35. Dolk $\mathrm{H}$. The predictive value of microcephaly during the first year of life for mental retardation at seven years. Dev Med Child Neurol. 1991;33(11):974-83. https://doi. org/10.1111/j.1469-8749.1991.tb14813.x PMID: 1743426

36. van der Linden V, Pessoa A, Dobyns W, Barkovich AJ, Júnior HV, Filho ELR, et al. Description of 13 Infants Born During October 2015-January 2016 With Congenital Zika Virus Infection Without Microcephaly at Birth - Brazil. MMWR Morb Mortal Wkly Rep. 2016;65(47):1343-8. https://doi.org/10.15585/mmwr. mm6547e2 PMID: 27906905

37. Alarcon A, Martinez-Biarge M, Cabañas F, Quero J, García-Alix A. A Prognostic Neonatal Neuroimaging Scale for Symptomatic Congenital Cytomegalovirus Infection. Neonatology. 2016;110(4):277-85. https://doi.org/10.1159/000446690 PMID: 27344149

38. Kwak M, Yum M-S, Yeh H-R, Kim H-J, Ko T-S. Brain Magnetic Resonance Imaging Findings of Congenital Cytomegalovirus Infection as a Prognostic Factor for Neurological Outcome. Pediatr Neurol. 2018;83:14-8. https://doi.org/10.1016/j. pediatrneurol.2018.03.008 PMID: 29681488

39. Victora CG, Schuler-Faccini L, Matijasevich A, Ribeiro E, Pessoa A, Barros FC. Microcephaly in Brazil: how to interpret reported 
numbers? Lancet. 2016;387(10019):621-4. https://doi. org/10.1016/S0140-6736(16)00273-7 PMID: 26864961

40. Sanz Cortes M, Rivera AM, Yepez M, Guimaraes CV, Diaz Yunes I, Zarutskie A, et al. Clinical assessment and brain findings in a cohort of mothers, fetuses and infants infected with ZIKA virus. Am J Obstet Gynecol. 2018;218(4):440.e1-36. https:// doi.org/10.1016/j.ajog.2018.01.012 PMID: 29353032

41. Levine D, Jani JC, Castro-Aragon I, Cannie M. How Does Imaging of Congenital Zika Compare with Imaging of Other TORCH Infections? Radiology. 2017;285(3):744-61. https://doi. org/10.1148/radiol.2017171238 PMID: 29155634

\section{License and copyright}

This is an open-access article distributed under the terms of the Creative Commons Attribution (CC BY 4.0) Licence. You may share and adapt the material, but must give appropriate credit to the source, provide a link to the licence, and indicate if changes were made.

This article is copyright of the authors or their affiliated institutions, 2018. 